\title{
Etnografi Komunikasi Masyarakat Taneyan Lanjhang Sebagai Identitas Budaya Pamekasan
}

\section{Samantha Bella Puri Bahesa1*, Nurudin²}

${ }^{1}$ Program Studi Ilmu Komunikasi, Universitas Muhammadiyah Malang, Malang, Indonesia

\section{ART I CLE IN F O}

Article history:

Received July 06, 2021

Revised July 09, 2021

Accepted Ausgust 4, 2021

Available online October 25, 2021

Kata Kunci:

Etnografi Komunikasi, Identitas

Budaya, Tradisi Lisan

Keywords:

Ethnography Of Communication,

Cultural Identity, Oral Tradition

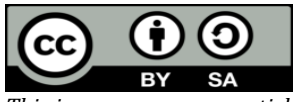

This is an open access article under the $C C$ BY-SA license.

Copyright (C) 2021 by Author. Published by Universitas Pendidikan Ganesha.

\begin{abstract}
A B S T R A K
Komunikasi dan kebudayaan tidak dapat dipisahkan dalam kehidupan manusia. Peran dari komunikasi dalam hal ini untuk menyampaikan pesan yang berkaitan dengan budaya itu sendiri. Dalam hal ini, perlu adanya pemahaman pola komunikasi yang dilakukan dalam menyampaikan pesan terkait kebudayaan tersebut. Tujuan dari penelitian ini yakni mengetahui dan menguraikan kehidupan kebudayaan dan pola-pola komunikasi yang terdapat dalam suatu daerah. Penelitian ini merupakan jenis penelitian etnografi komunikasi, dengan populasi yakni seluruh masyrakat daerah. Penarikan sampel dilakukan dengan menggunakan Teknik purposive sampling, dengan kriteria tertentu. Adapun sampel dalam penelitian ini yakni 1 orang masyrakat asli yang menjabat sebagai seorang kepala dusun. Pengumpulan data dalam penelitian dilakukan menggunakan metode observasi dan wawancara Bersama sampel penelitian. Data hasil penelitian kemudian dianalisis menggunakan analisis deskriptif kualitatif, yakni dengan cara mendeskripsikan data hasil wawancara dan dokumentasi. Hasil penelitian menunjukkan bahwa masyarakat di di suatu daerah melaksanakan komunikasi selain secara verbal dengan selalu melibatkan hal kebudayaan yang terdapat pesan terhadap kelompoknya. Dalam mewariskan nilai-nilai budaya yang ada dalam pemukiman, masyarakatnya secara terus-menerus melakukan tradisi kebudayan yang ada sehingga telah menjadi pola bagi kelompoknya. Penggunaan bahasa daerah lebih banyak digunakan dalam proses komunikasi sehari-hari serta digunakan dalam kegiatan upacara keagamaan.
\end{abstract}

\section{A BS TRACT}

Communication and culture cannot be separated in human life. The role of communication in this case is to convey messages related to the culture itself. In this case, it is necessary to understand the pattern of communication used in conveying messages related to the culture. The purpose of this research is to find out and describe the cultural life and communication patterns that exist in an area. This research is a type of communication ethnographic research, with a population of all local people. Sampling was done using purposive sampling technique, with certain criteria. The sample in this study was 1 native who served as a hamlet head. Data collection in the study was carried out using the method of observation and interviews with the research sample. The research data were then analyzed using qualitative descriptive analysis, namely by describing the data from interviews and documentation. The results of the study indicate that people in an area carry out communication other than verbally by always involving cultural matters that contain messages for their groups. In passing on the cultural values that exist in the settlements, the people continuously carry out the existing cultural traditions so that they have become patterns for their groups. The use of regional languages is more widely used in the daily communication process and is used in religious ceremonies.

\section{PENDAHULUAN}

Indonesia merupakan Negara yang memiliki keberagaman suku, agama, budaya, bahasa, dan adat istiadat. Kehidupan masyarakat Indonesia selalu berdampingan dengan berbagai kebudayaan yang telah diwariskan secara turun temurun oleh nenek moyang. Budaya memiliki pengaruh yang sangat besar terhadap kehidupan karena di dalam budaya terkandung nilai-nilai, pedoman, norma, yang merupakan standar yang dibangun oleh masyarakat sejak dulu dan telah dipercayai dan dilaksanakan secara turuntemurun (Setiawan, 2018; Setyaningrum \& Diah, 2018; Yoga, 2019). Budaya sendiri terbentuk berdasarkan pengalaman atau cara berpikir manusia (Purwanto, 2019; Wedasuwari, 2020). Dalam hal ini, kebudayaan sangat mempengaruhi perilaku manusia karena representasi dari budaya adalah manusia yang menganut budaya itu sendiri (Sati et al., 2021). Peraturan terkait tingkah laku masyarakat diajarkan dan dihargai serta dipegang teguh sebagai landasan dalam bertingkah laku karena kebudayaan merupakan suatu pedoman dasar bagi masyarakat berdasarkan kebiasaan yang didapat sebagai anggota masyarakat (Zuriatina, 2020). Hal ini menunjukkan bahwa budaya tidak hanya sebagai identitas perorangan saja, melainkan sebagai identitas kelompok. Kebudayaan dapat dikatakan sebagai identitas kelompok apabila setiap individu 
merasa memiliki kesamaan akan menyatu menjadi sebuah kelompok (Sugihartati, 2019; Utami, 2018). Identitas kelompok ini kemudian akan berkembang menjadi indentitas budaya yang membentuk sebuah karakteristik ataupun ciri-ciri dari sebuah kebudayaan yang dianut oleh sekelompok orang yang memiliki persepsi terhadap simbol-simbol dan makna yang sama (Kholis \& Kurnia, 2021). Salah satu kebudayaan yang berkembang di masyarakat yakni kebudayaan Taneyan Lanjhang. Taneyan Lanjhang merupakan sebuah perkampungan atau hunian tradisional masyarakat Pamekasan (Safeyah et al., 2018). Konsep hunian Taneyan Lanjhang, sangat erat kaitannya dengan sistem kekerabatan Madura dan pendiriannya memiliki tatacara dan peraturan sosial yang didasarkan pada ajaran keagamaan (Hermanto \& Hendriani, 2021). Susunan rumah didasarkan pada urutan dalam keluarga. Arah letak Barat sampai Timur merupakan arah yang menunjukkan tua muda (Safeyah et al., 2018). Dengan adanya sistem seperti itu mengakibatkan hubungan kekeluargaan yang sangat erat sehingga hal tersebut menjadi sebuah ciri khas.

Masyarakat yang terdapat di dalam pemukiman Taneyan Lanjhang ini masih sangat menjunjung nilai-nilai kebudayaan yang telah dilakukan secara turun-temurun (Wahid \& Juhdi, 2018). Di tengah masyarakat yang modern, masyarakat Taneyan Lanjhang terus berusaha menanamkan nilai-nilai budaya yang telah dianut atau dipercayai sejak dahulu (Ainsworth et al., 2019). Nilai-nilai budaya berpijak pada warisan budaya dari orang terdahulu dan praktik dari masyarakat dan meresap sehingga menjadi sebuah kebiasaan di dalam suatu masyarakat (Nurcahyo \& Yulianto, 2021). Misalnya, dalam menamkan nilai sopan santun masyarakat pemukiman Taneyan Lanjhang menggunakan struktur pintu dapur yang lebih pendek sebagai komunikasi dalam kelompoknya, sehingga ketika masuk ke dalam dapur harus menunduk. Hal ini sangat menarik, karena segala yang dilakukan oleh masyarakat tersebut memiliki nilai-nilai yang sangat kuat di dalam kehidupan bermasyarakat. Kebudayaan taneyan lanjang dapat dikatakan sebagai sebuah identitas karena masyarakat yang berada di dalam hunian tersebut memiliki presepsi atau cara pandang yang sama mengenai simbol-simbol dan makna yang terdapat dalam pemukiman Taneyan Lanjhang ini. Jika tidak memiliki presepsi yang sama, maka Taneyan Lanjhang ini tidak akan terbentuk. Ciri-ciri dari pemukiman Taneyan Lanjhang sendiri adalah halaman yang panjang dan susunan rumah di dalam pemukiman ini didasarkan pada urutan tua-muda dalam keluarga. Hubungan keluarga kandung sangat erat di pemukiman Taneyan Lanjhang ini. Hanya saja di era modern seperti saat ini, pemukiman Taneyan Lanjhang mulai punah dan sangat sulit ditemukan meskipun di daerah pedesaan sekalipun. Pemukiman Taneyan Lanjhang hanya dapat ditemui dalam satu desa dan hanya terdapat 1 pemukiman saja yang masih bertahan. Padahal, di dalam pemukian Taneyan Lanjhang ini terdapat banyak nilai-nilai yang sangat menarik untuk dipertahankan di zaman modern seperti saat ini. Dalam segi bentuk hunian dan arsitektur, pemukiman ini sangat menarik dan mengandung nilai-nilai kekeluargaan. Jadi, sangat disayangkan jika hunian tidak dipertahankan.

Upaya yang dapat dilakukan untuk memperkenalkan kebudayaan Taneyan Lanjhang kepada masyarakat yakni dengan cara mengkomunikasikan kembali kebudayaan-kebudayaan Taneyan Lanjhang kepada masyrakat sekitar atau penduduk asli melalui proses etnografi. Etnografi dikenal sebagai ilmu pengetahuan yang memfokuskan kepada upaya menggambarkan cara-cara hidup manusia dan mengacu kepada deskripsi sosial tentang manusia dan landasan budaya kemanusiaan. Etnografi komunikasi merupakan usaha untuk menguraikan kehidupan dan kebudayan suatu kelompok masyarakat (Ediyanti et al., 2021). Dalam hal ini, tugas dari etnografi komunikasi adalah mengkaji mengenai pola-pola komunikasi sebuah komunitas budaya (Fitriyani et al., 2022; Istiyanto \& Novianti, 2018). Maka, etnografi berusaha mengkaji mengenai kehidupan manusia dan kebudayaan suatu masyarakat, sedangkan untuk etnografi komunikasi sendiri memfokuskan diri kepada bahasa yang digunakan oleh kelompok masyarakat (Handayani, 2021; Nugroho \& Purwati, 2019).

Etnografi bertujuan untuk menyajikan sebuah interpretasi atau pandangan mengenai kebudayaan dalam masyarakat (Wirman et al., 2018). Masyarakat yang berada di pemukiman Taneyan Lanjhang ini tidak terlepas dari adanya sebuah komunikasi, karena tidak dapat dipungkiri bahwa setiap kehidupan manusia tidak terlepas dari komunikasi. Maka disini etnografi komunikasi berperan dalam menelaah megenai kehidupan kebudayaan dan komunikasi yang digunakan di dalam masyarakat di pemukiman Taneyan Lanjhang. Salah satu tradisi yang dapat dikaji yakni tradiri lisan masyarakat di pemukiman Taneyan Lanjhang. Komunikator yang terampil di dalam tradisi lisan akan membuat informasi yang sulit diperoleh menjadi menonjol, mudah untuk diingat, mudah diterima untuk ditransmisikan ulang (Schniter et al., 2018). Tradisi lisan merupakan sebuah penyampaian tradisi atau kebiasaan secara turun-temurun secara lisan (Gusti et al., 2021). Di sini, dalam penyampaian tradisi tersebut tidak hanya mengandung unsur verbal, melainkan unsur non-verbal.

Setiap kebudayaan yang berkembang di masyarakat memiliki tradisi lisannya masing-masing, hal ini dapat dilihat dari beberapa hasil penelitian yang telah dilakukan sebelumnya. Hasil penelitian sebelumnya mengungkapkan bahwa etnografi komunikasi peristiwa tutur yang terjadi pada masyarakat padoe tidak lepas dari konteks kebudayaan yang ada yang tercakup pada aturan atau norma berbahasa 
serta pantangan-pantanga kosakata yang tidak bisa diucapkan dalam kondisi tertentu (Beta et al., 2020). Penelitian lainnya juga mengungkapkan bahwa kata-kata yang digunakan oleh masyarakat nelayan kecamatan Samatiga Kabupaten Aceh Barat yakni bahasa aceh dan lebih bersifat harapan kepada nelayan, sedangkan kata-kata halus dan do'a digunakan pada saat tadarus dan berdo'a memohon kepada Allah SWT (Maifianti \& Raidayani, 2021). Penelitian selanjutnya juga menyatakan bahwa pola komunikasi masyarakat Ulakan Tapakis Kabupaten Padang Pariaman yang ada dalam prosesi basapa yaitu pola komunikasi primer, dikarenakan prosesi yang terdapat dalam tradisi basapa banyak memakai lambang verbal dan nonverbal (Ediyanti et al., 2021). Berdasarkan beberapa hasil penelitian tersebut dapat dikatakan bahwa setiap tradisi serta kebudayaan yang ada di suatu daerah memiliki etnografi komunikasi yang berbeda-beda bergantung pada kebudayaan yang berkembang. Hanya saja pada penelitian sebelumnya belum terdapat kajian mengenai etnografi komunikasi masyarakat Taneyan Lanjhang sebagai identitas budaya Pamekasan, sehingga penelitian ini difokuskan pada kajian tersebut dengan tujuan untuk mengetahui dan menguraikan kehidupan kebudayaan dan pola-pola komunikasi yang terdapat dalam pemukiman Taneyan Lanjhang.

\section{METODE}

Penelitian ini merupakan jenis penelitian kualitatif etnografi komunikasi. Penelitian kualitatif ini bertujuan untuk menguraikan mengenai fenomena yang dialami oleh subjek dengan menggunakan Bahasa. Kerangka konseptual dalam etnografi, melibatkan langsung seorang peneliti ke dalam budaya kelompok akan memungkinkan peneliti untuk melihat dunia dari perspektif kelompok tersebut dan melihat yang akan memberikan pemahaman tentang perilaku dan keyakinan kelompok (Yusanto, 2020). Etnografi komunikasi mengkhususkan kepada kajian terhadap pola komunikasi yang digunakan manusia dalam kelompok masyarakat tutur (Inayah \& Abdi, 2018). Populasi dalam penelitian ini yakni seluruh masyarakat di pemukiman Taneyan Lanjang. Penarikan sampel penelitian dilakukan dengan menggunakan purposive sampling. Penentuan sampel didasarkan kepada kriteria tertentu. Pertama, mengetahui mengenai informasi terkait pemukiman Taneyan Lanjhang. Kedua, sebagai pelaku budaya atau ikut melakukan kebudayaan di Taneyan Lanjhang. Ketiga, tinggal di pemukiman Taneyan Lanjhang atau merupakan bagian dari Taneyan Lanjhang. Adapun sampel penelitian yang didapatkan yakni 1 orang masyarakat yang bernama Adi Bahri dan merupakan keturunan ke-4 dari leluhur yang berada di pemukiman Taneyan Lanjhang. Selain itu, beliau juga menjabat sebagai kepala Dusun di daerah tersebut. Pengumpulan data dalam penelitian dilakukan menggunakan metode observasi dan wawancara Bersama sampel penelitian. Data hasil penelitian kemudian dianalisis menggunakan analisis deskriptif kualitatif, yakni dengan cara mendeskripsikan data hasil wawancara dan dokumentasi.

\section{HASIL DAN PEMBAHASAN}

Hasil

Hasil wawancara bersama sampel penelitian menunjukkan bahwa sebagai masyarakat tradisional yang masih bertahan di tengah-tengah masyarakat modern, masyarakat di pemukiman Taneyan Lanjhang tetap konsisten dalam melestarikan nilai-nilai budaya yang ada. Ditinjau berdasarkan tradisi lisan yang terdiri dari tradisi lisan yang berbentuk murni lisan, tradisi lisan yang terdiri dari campuran antara unsur lisan dan unsur bukan lisan, serta tradisi lisan material bukan lisan yang dibagi menjadi tradisi lisan material dan non material. Masyarakat di pemukiman ini percaya bahwa sesuatu yang telah diturunkan oleh leluhur mereka harus terus dilanjutkan. Taneyan Lanjhang berasal dari kata taneyan yang berarti halaman dan lanjhang yang berarti panjang. Dalam hal ini, Taneyan Lanjhang dapat dipahami sebagai halaman yang panjang. Di dalam Taneyan Lanjhang yang terdapat di Dusun Buddhagan 1 ini, terdapat 11 roma (rumah) yang dimiliki oleh sekelompok keluarga besar yang telah dibangun sejak lama dan merupakan warisan secara turun-temurun. Dalam hunian Taneyan Lanjhang tersebut terdapat berapa unsur yang mengkonstruksi yaitu roma (rumah), kobhung (langgar), dapoor (dapur), dan kandang. Dalam masing-masing tempat tersebut memiliki fungsinya masing-masing. Roma (rumah) yang merupakan tempat tinggal yang hanya dikhususkan untuk perempuan dan anak-anak dan memiliki sifat yang sangat tertutup. Kobhung atau langgar dalam Kamus Besar Bahasa Indonesia (KBBI) merupakan masjid kecil tempat mengaji atau shalat. Selain digunakan sebagai tempat untuk melaksanakan kegiatan keagamaan, kobhung (langgar) di Taneyan Lanjhang juga memiliki fungsi sebagai tempat untuk menerima tamu, tempat istirahat, dan sebagai tempat tidur bagi laki-laki. Selanjutnya bagian Dapoor (dapur) pada hunian Taneyan Lanjang memiliki fungsi yang sama dengan dapur lainnya, yakni sebagai tempat untuk menyimpan bahan makanan bahkan mengolahnya menjadi makanan. Hanya saja perbedaan dengan dapur yang lainnya, dapur di pemukiman Taneyan Lanjhang ini menyatu dengan kandang yang merupakan tempat untuk memelihara ternak sapi dan letak dapur ini tepat di sebelah selatan. 
Komponen roma (rumah) dan kobhung (langgar) merupakan tempat istirahat atau tidur bagi penghuni Taneyan Lanjhang. Namun hal ini, dibedakan bahwa anak-anak dan wanita tidur di roma (rumah) sedangkan laki-laki tidur di kobhung (langgar). Hal ini, dimaksudkan bahwa seorang laki-laki harus menjaga wanita dan anak-anaknya. Letak kobhung (langgar) terletak di ujung sebelah barat yang dibuat agar menghadap kepada akses masuk area Taneyan Lanjhang tersebut. Letak roma (rumah) berada di sebelah utara. Kegiatan para wanita dan anak-anak pun dapat jelas terlihat. Dalam hal ini, seorang komunikator dalam menyampaikan pesannya bahwa seorang laki-laki memiliki tanggung jawab yang besar terhadap keluarganya melalui letak posisi kobhung (langgar) yang dapat melihat semua kegiatan yang terjadi di Taneyan Lanjhang. Dalam struktur bangunan roma (rumah) ada yang terpisah dengan bangunan rumah yang lainnya dan ada yang menyatu atau tersambung. Biasanya lantai di pemukiman Taneyan Lanjhang ini menggunakan plesteran, namun karena dipengaruhi oleh modernisasi ada roma (rumah) yang lantainya menggunakan keramik. Roma (rumah) memiliki sifat yang tertutup karena di dalam roma (rumah) hanya terdiri dari satu ruangan saja yang digunakan untuk tempat beristirahat bagi perempuan dan anak-anak tanpa adanya sekat. Hal ini, mengakibatkan adanya komunikasi yang sangat intens antara anak-anak dan ibunya karena dalam hal ini tidak ada penghalang yang membatasinya. Dalam sehari-hari, proses komunikasi berjalan dengan baik dengan anggota kelompoknya karena meski terpisah oleh tempat tinggal, mereka di waktu senggang akan berkumpul di salah satu teras rumah untuk melakukan proses komunikasi.

Struktur bangunan yang terdapat di pemukiman Taneyan Lanjhang ini selalu berukuran pendek, dari struktur pintu roma (rumah), pintu dapoor (dapur) dan kandang, hingga struktur bangunan kobhung (langgar). Dengan begitu, ketika ingin mengaksesnya, setiap orang harus menunduk. Hal ini dimaksudkan sebagai sebuah pesan pengajaran kepada kelompoknya agar selalu memiliki sikap andhap asor yang berarti bersikap sopan, santun, menghormati orang lain, serta bersikap tidak sombong. Hal tersebut, meyebabkan setiap orang yang berada di lingkungan tersebut sangat santun terhadap sesama kelompoknya bahkan kepada orang lain yang bukan merupakan bagiannya. Dalam menghormati tamu, masyarakat di pemukiman Taneyan Lanjhang ini menghidangkan makanan kepada tamunya. Hidangan disini bukan dalam bentuk camilan ataupun makanan ringan, melainkan nasi. Hidangan seperti nasi tersebut dimaksudkan sebagai sebuah penghormatan kepada tamunya bahwa masyarakat di Taneyan Lanjhang menerima dengan senang hati. Dalam segi kebudayaan, masyarakat di pemukiman Taneyan Lanjhang masih sangat kental dengan nilai-nilai budayanya. Hal ini, ditandai dengan masih terjaganya dan masih tetap terlaksanaya tradisi-tradisi yang ada. Setiap satu tahun sekali, masyarakat di pemukiman Taneyan Lanjhang melaksanakan acara pengajian yang berlokasi di Bhuju' Jepara. Bhuju' memiliki arti makam atau kuburan sedangkan Jepara disini memiliki arti nama dari orang terdahulu yang mewariskan pemukiman Taneyan Lanjhang ini dan merupakan kepala desa pertama. Dapat dikatakan bahwa Bhuju' Jepara merupakan kuburan atau makam orang yang paling disegani dan dihormati sejak dahulu. Acara pengajian atau selamatan ini dikenal dengan nama "Rokat Bhuju' Jepara". Dalam melakasanakan acara pengajian ini, orang yang hadir tidak hanya sebatas masyarakat pemukiman Taneyan Lanjhang saja, melainkan orang dari dusun lain. Biasanya masyarakat yang hadir dalam pengajian ini, selalu membawa uang ataupun makanan yang berupa nasi yang nantinya akan dibagikan kepada tiap-tiap orang. Hal ini, menggambarkan rasa syukur dan menerapkan nilai-nilai kemanusiaan yaitu agar selalu berbagi kepada orang lain.

Setiap hari kamis malam, akan ada masyarakat yang mengaji di Bhuju' Jepara guna menghatamkan Al-Qur'an. Hal tersebut menjadi hal yang biasa dilakukan oleh masyarakat dari orang dewasa hingga anakanak di lingkungan Taneyan Lanjhang guna mendekatkan diri kepada Allah swt. Selain itu, hataman AlQur'an dilakukan di Bhuju' Jepara untuk terus mengingat leluhur mereka. Masyarakat di Taneyan Lanjhang dalam menunjukkan segala rasa syukurnya kepada Allah swt akan melaksanakan acara selamatan. Misalnya, acara Selamedhan Jagung (selamatan jagung). Acara ini dilakukan pada saat buah jagung yang mereka tanam masih muda yang berumur sekitar 75-80 hari. Dalam acara selamatan ini, setiap orang akan membawa jagung yang berasal dari lahannya masing-masing yang telah mereka rebus. Hasil rebusan tersebut akan mereka bawa ketika shalat Jum'at yang kemudian akan mereka tukar dengan jagung yang orang lain bawa. Selain itu, selamatan ini juga biasanya dilakukan dengan mengadakan pengajian yang akan diakhiri dengan saling tukar menukar jagung. Adapun maksud dari acara selamatan ini adalah sebagai salah satu bentuk komunikasi kepada Tuhan-Nya, yang mana mereka bersyukur atas rezeki yang mereka dapatkan dan berharap dilancarkan hingga panen. Dalam masyarakat Taneyan Lanjhang juga terdapat budaya "Aridan Sapi" yang diadakan setiap bulan. Budaya ini muncul karena masyarakat yang berada di daerah pemukiman Taneyan Lanjhang rata-rata memiliki ternak sapi. "Aridan Sapi" ini merupakan sebuah acara yang dimana, sapi akan di hias dan akan di pamerkan. Orang yang mengiringi sapi hias tersebut akan menggunakan baju tradisional seperti pesak. Kebudayaan ini dimaksudkan untuk memberikan motivasi kepada peternak lain yang ternak sapinya kurus sehingga semangat dalam merawatnya. Komunikasi disini berupa pesan tersirat yang terdapat dalam kebudayaan ini, yaitu dalam memamerkan ternak sapi akan 
menimbulkan pemikiran bahwa "sapi saya lebih atau kurang dari sapi dia". Hal ini menimbulkan adanya komunikasi dan motivasi.

\section{Pembahasan}

Berdasarkan hasil penelitian dapat diketahui bahwa perilaku komunikasi dalam masyarakat Taneyan Lanjhang cenderung menggunakan simbol yang diciptakan bersama kelompoknya dan memiliki pemahaman yang sama terkait simbol-simbol tersebut. Peristiwa-peristiwa komunikasi terjadi secara alami yang didasarkan pada pola pikir dan tingkah laku masyarakatnya yang memiliki pesan dan makna. Dalam menyampaikan pesan terhadap kelompoknya, masyarakat di pemukiman Taneyan Lanjhang dalam melaksanakan komunikasi selain secara verbal juga selalu melibatkan hal kebudayaan yang terdapat pesan terhadap kelompoknya (non-verbal). Selain digunakan dalam proses komunikasi dalam kehidupan seharihari Bahasa lisan yang digunakan oleh masyarakat Taneyan Lanjhang juga digunakan untuk menyebutkan bagian-bagian rumah serta berbagai ritual keagamaan. Hasil tersebut menunjukkan bahwa masyrakat Taneyan Lanjhang memiliki Bahasa kusus dalam proses komunikasinya. Bahasa pada dasarnya merupakan media yang dapat digunakan untuk memberikan atau menyampaikan suatu informasi atau penjelasan terhadap lawan bicara. Bahasa menjadi jantung dari sebuah proses komunikasi, sehingga Bahasa harus dilestarikan dan dijaga keutuhannya (Arisandy et al., 2019; Nurhadi, 2017). Penggunaan Bahasa yang disesuaikan dengan kebudayaan masyarakat setempat akan memudahkan seseorang untuk bersosialisasi, bertukar pikiran, menyampaikan gagasan dan berinteraksi satu sama lain (Hadiyatullah et al., 2018; Prathiwi, 2020).

Bangsa Indonesia merupakan bangsa yang terdiri atas berbagai suku, adat isitiadat dan kebudayaan. Sehingga tidak dapat dipungkiri bahwa terdapat berbagai macam Bahasa daerha yang berkembang di negara Indonesia. Penggunaan Bahasa daerah tentunya hanya akan dipahami oleh masyarakat daerah tersebut, sehingga untuk membentuk persatuan dan kesatuan maka bangsa Indonesia membuat sebuah Bahasa resmi yakni Bahasa Indonesia (Putri, 2018; Widianto, 2018). Bahasa Indonesia menjadi Bahasa resmi yang digunakan oleh masyarakat Indonesia untuk berkomunikasi satu sama lain setelah penggunaan Bahasa daerah (Bhakti, 2020; Prathiwi, 2020). Adanya Bahasa resmi akan memudahkan proses komunikasi masyarakat antar suku dan pulau. Walaupun sudah terdapat Bahasa persatuan yakni Bahasa Indonesia, penggunaan Bahasa daerah tidak dapat ditinggal begitu saja, hal ini dikarenakan Bahasa daerah merupakan salah satu bentuk kebudayaan yang diturunkan oleh nenek moyang secara turun temurun (Budiarto, 2020). Bahasa daerah pada dasarnya merupakan Bahasa atau pola komunikasi yang digunakan oleh sekelompok masyarakat yang mendiami suatu wilayah (Hidayatullah, 2018; Putri, 2018). Bahasa yang digunakan daerah yang satu tentunya akan berbeda dengan Bahasa daerah lainnya. Bahasa daerah umumnya digunakan dalam aktifitas kehidupan sehari-hari dan umumnya juga digunakan dalam proses pemujaan pada upacara keagamaan (Mogot, 2020). Bahasa daerah juga dapat disebut sebagai Tradisi lisan yang merupakan sebuah penyampaian tradisi atau kebiasaan secara turuntemurun secara lisan (Kusmana et al., 2020). Penyampaian tradisi lisan tidak hanya mengandung unsur verbal, melainkan juga mengandung unsur non-verbal.

Setiap kebudayaan yang berkembang di masyarakat memiliki tradisi lisannya masing-masing. Hal ini dapat dilihat dari analisis hasil penelitian yang kemudian didukung oleh hasil penelitian terdahulu. Hasil penelitian yang telah dilakukan sebelumnya mengungkapkan bahwa etnografi komunikasi peristiwa tutur yang terjadi pada masyarakat padoe tidak lepas dari konteks kebudayaan yang ada yang tercakup pada aturan atau norma berbahasa serta pantangan-pantanga kosakata yang tidak bisa diucapkan dalam kondisi tertentu (Beta et al., 2020). Penelitian lainnya juga mengungkapkan bahwa kata-kata yang digunakan oleh masyarakat nelayan kecamatan Samatiga Kabupaten Aceh Barat yakni bahasa aceh dan lebih bersifat harapan kepada nelayan, sedangkan kata-kata halus dan do'a digunakan pada saat tadarus dan berdo'a memohon kepada Allah SWT (Maifianti \& Raidayani, 2021). Penelitian selanjutnya juga menyatakan bahwa pola komunikasi masyarakat Ulakan Tapakis Kabupaten Padang Pariaman yang ada dalam prosesi basapa yaitu pola komunikasi primer, dikarenakan prosesi yang terdapat dalam tradisi basapa banyak memakai lambang verbal dan nonverbal (Ediyanti et al., 2021). Berdasarkan hasil penelitian yang didukung oleh hasil penelitian terdahulu dapat dikatakan bahwa bahasa daearah atau pola komunikasi setiap daerah berbedabeda. Pola komunikasi yang digunakan umumnya juga hanya dipahami masyrakat daerah setempat yang digunakan dalam proses komunikasi sehari-hari dan digunakan dalam mantra pemujaan acara keagamaan.

\section{SIMPULAN}

Berdasarkan penelitian yang dilakukan, maka dapat disimpulkan bahwa perilaku komunikasi dalam masyarakat Taneyan Lanjhang cenderung menggunakan simbol yang diciptakan bersama kelompoknya dan memiliki pemahaman yang sama terkait simbol-simbol tersebut. Peristiwa-peristiwa 
komunikasi terjadi secara alami yang didasarkan pada pola pikir dan tingkah laku masyarakatnya yang memiliki pesan dan makna. Dalam menyampaikan pesan terhadap kelompoknya, masyarakat di pemukiman Taneyan Lanjhang dalam melaksanakan komunikasi selain secara verbal juga selalu melibatkan hal kebudayaan yang terdapat pesan terhadap kelompoknya (non-verbal). Untuk bahasa yang digunakan dalam berkomunikasi, mereka menggunakan bahasa sopan yang dipahami oleh kelompoknya. Dalam bertukar pesan, masyarakat di pemukiman Taneyan Lanjhang memilih secara bertatap muka yang disampaikan dengan cara lisan kepada perorangan maupun dilakukan dengan cara berkelompok di suatu tempat. Masyarakat taneyan lanjhang juga menggunakan komunikasi non-verbal dalam berinteraksi dengan kelompoknya. Hal ini didasarkan melalui simbol dan pemaknaan terhadap tradisi kebudayaan yang dilakukan bersama-sama dengan kelompoknya yang dimaksudkan untuk menyampaikan pesan-pesan tersirat. Dalam mewariskan nilai-nilai budaya yang ada dalam pemukiman Taneyan Lanjhang ini, masyarakatnya secara terus-menerus melakukan tradisi kebudayan yang ada sehingga telah menjadi pola bagi kelompoknya. Hal tersebut memicu adanya keharusan untuk dilakukan bagi penerus-penerusnya.

\section{DAFTAR PUSTAKA}

Ainsworth, G. B., Kenter, J. O., O’Connor, S., Daunt, F., \& Young, J. C. (2019). A fulfilled human life: Eliciting sense of place and cultural identity in two UK marine environments through the Community Voice Method. Ecosystem Services, 39(1), 100992. https://doi.org/10.1016/j.ecoser.2019.100992.

Arisandy, D., Rizkika, D. P., \& Astika, T. D. (2019). Eksistensi Bahasa Indonesia Pada Generasi Milenial Di Era Industri 4.0. Pendidikan Bahasa Dan Sastra Indonesia, 3(2), 247-251. https://jurnal.uisu.ac.id/index.php/Bahastra/article/view/3180.

Beta, P., Salvia, R., \& Besse Herdiana. (2020). Etnografi Komunikasi Tata Cara Bertutur Masyarakat Suku Padoe. Jurnal Onoma: Pendidikan, Bahasa, Dan Sastra, 6(1), 527-532. https://doi.org/10.30605/onoma.v6i1.274.

Bhakti, W. P. (2020). Pergeseran Penggunaan Bahasa Jawa Ke Bahasa Indonesia Dalam Komunikasi Keluarga Di Sleman. Jurnal Skripta, 6(2), 28-40. https://doi.org/10.31316/skripta.v6i2.811.

Budiarto, G. (2020). Dampak Cultural Invasion terhadap Kebudayaan Lokal: Studi Kasus Terhadap Bahasa Daerah. Pamator Journal, 13(2), 183-193. https://doi.org/10.21107/pamator.v13i2.8259.

Ediyanti, R., Mulyodiharjo, S., \& Zumiarti. (2021). Etnografi Komunikasi Basapa di Ulakan Tapakis Kabupaten Padang Pariaman. Jurnal Ilmiah Ekotrans \& Erudisi, 1(1), 38-51. https://doi.org/10.31933/jiee.v1i1.95.

Fitriyani, F., Adil, M., \& Bukhori, K. (2022). Pola Komunikasi Ritual Kembar Mayang: Kajian Etnografi Komunikasi pada Etnis Jawa. Intizar, 26(2), 81-94. https://doi.org/10.19109/intizar.v26i2.7854.

Gusti, U. A., Islami, A., Ardi, A., Almardiyah, A., Rahayu, R. G., \& Tananda, O. (2021). Tinjauan Penyebaran Tradisi Lisan Di Sumatera Barat. Jurnal Adat Dan Budaya Indonesia, 3(1), 1. https://doi.org/10.23887/jabi.v3i1.39261.

Hadiyatullah, S., Yusuf, N., \& Zuriah, N. (2018). Penumbuhan Rasa Nasionalisme Dan Cinta Budaya Indonesia Melalui Program "Kamsi" Pada Siswa SMP Negeri 1 Batu. Jurnal Civic Hukum, 3(1), 111. https://doi.org/10.22219/jch.v3i1.7733.

Handayani, P. (2021). Etnografi Komunikasi Pada Etnis Arab Dan Etnis Sunda Di Kelurahan Empang Kota Bogor. Jurnal Media Bahasa, Sastra, Dan Wahana, 27(2). https://doi.org/10.33751/wahana.v27i2.4548.

Hermanto, H., \& Hendriani, A. S. (2021). Menelusuri Jejak Arsitektur Langgar Di Wonosobo. Jurnal Penelitian Dan Pengabdian Kepada Masyarakat UNSIQ, 8(3), 268-276. https://doi.org/10.32699/ppkm.v8i3.2038.

Hidayatullah, A. (2018). Pola Komunikasi Tokoh Adat Dalam Melestarikan Budaya Tradisional Suku Sambori. Journal Acta Diurna, 14(2), 84. https://doi.org/10.20884/1.actadiurna.2018.14.2.1346.

Inayah, S. S., \& Abdi, M. A. (2018). Etnografi Komunikasi Muslimah Bercadar Di Samarinda. Jurnal Lenteran, 2(2). https://doi.org/10.21093/lentera.v2i2.1374.

Istiyanto, S. B., \& Novianti, W. (2018). Etnografi Komunikasi Komunitas yang Kehilangan Identitas Sosial dan Budaya di Kabupaten Cilacap. Jurnal Kajian Komunikasi, 6(1), 64. https://doi.org/10.24198/jkk.v6i1.15213.

Kholis, M. . N., \& Kurnia, W. (2021). Suling Dewa sebagai Identitas Simbolik Masyarakat SasakKuno-Kute di Karang Bajo bayan Lombok Utara. Jurnal Kajian Seni, 08(01), 15-35. https://doi.org/https://doi.org/10.22146/jksks.64498.

Kusmana, A., Izar, J., \& Hardi, S. (2020). Pemetaan Tradisi Lisan Di Provinsi Jambi. Titian: Jurnal Ilmu Humaniora, 04(1), 1-14. https://doi.org/10.22437/titian.v4i1.9202.

Maifianti, K. S., \& Raidayani, R. (2021). Etnografi Komunikasi Kanuri Laot Masyarakat Nelayan Kecamatan 
Samatiga Kabupaten Aceh Barat. Jurnal AGRISEP: Kajian Masalah Sosial Ekonomi Pertanian Dan Agribisnis, 20(01), 95-102. https://doi.org/10.31186/jagrisep.20.01.95-102.

Mogot, Y. (2020). Aktivitas Komunikasi Masyarakat Hindu Tamil Dalam Upacara Thaipusam Di Singapura. Jurnal Common, 3(2), 216-228. https://doi.org/10.34010/common.v3i2.2605.

Nugroho, O. C., \& Purwati, E. (2019). Etnografi Komunikasi Visual Pertunjukan Reyog Obyogan Ponorogo. Rekam, 15(1), 33-47. https://doi.org/10.24821/rekam.v15i1.3282.

Nurcahyo, R. J., \& Yulianto, Y. (2021). Menelusuri Nilai Budaya Yang Terkandung Dalam Pertunjukan Tradisional Wayang. Jurnal Pariwisata Dan Budaya, 12(2), 159-165. https://doi.org/10.31294/khi.v12i2.11440.

Nurhadi, Z. fachrul. (2017). Kajian Tentang Efektivitas Pesan Dalam Komunikasi. Jurnal Komunikasi Hasil Pemikiran Dan Penelitian, 1(1), 90-91. https://doi.org/ 10.10358/jk.v3i1.253.g295.

Prathiwi, G. L. A. (2020). Analisis Kendala Penggunaan Bahasa Dalam Pekerjaan Pada Masyarakat Sunda. Commentate: Journal of Communication Management, 1(2), 129. https://doi.org/10.37535/103001220202.

Purwanto, B. (2019). Perspektif Historis Kesadaran Kebangsaan Dan Kemerdekaan Indonesia Berdimensi Kebudayaan. Historia: Jurnal Pendidik Dan Peneliti Sejarah, 2(2), 125. https://doi.org/10.17509/historia.v2i2.16636.

Putri, N. W. (2018). Pergeseran Bahasa Daerah Lampung Pada Masyarakat Kota Bandar Lampung. Jurnal $\begin{array}{lll}\text { Penelitian } \quad \text { Humaniora, } & \text { 79(2), }\end{array}$ https://journals.ums.ac.id/index.php/humaniora/article/download/6810/4111.

Safeyah, M., Elviana, E., Takarini, N., \& Sutejo, A. (2018). The changes of the spatial pattern of tanean lanjang in kampung batik Tanjung Bumi. Tesa Arsitektur, 16(30), 73-83. https://doi.org/10.24167/tesa.v16i2.1123.

Sati, A. L., Marhamah, M., Nurhot, N., \& Dewi, U. (2021). Representasi Nilai Pancasila Dalam Kehidupan Berbudaya. Jurnal Syntax Fusion, 1(2), 1-11. https://doi.org/10.54543/fusion.v1i2.14.

Schniter, E., Wilcox, N. T., Beheim, B. A., Kaplan, H. S., \& Gurven, M. (2018). Information transmission and the oral tradition: Evidence of a late-life service niche for Tsimane Amerindians. Evolution and Human Behavior, 39(1), 94-105. https://doi.org/10.1016/j.evolhumbehav.2017.10.006.

Setiawan, D. (2018). Dampak Perkembangan Teknologi Informasi dan Komunikasi Terhadap Budaya. Jurnal Simbolika: Research and Learning in Communication Study, 4(1), 62. https://doi.org/10.31289/simbollika.v4i1.1474.

Setyaningrum, B., \& Diah, N. (2018). Budaya Lokal Di Era Global. Ekspresi Seni, 20(2), 102. https://doi.org/10.26887/ekse.v20i2.392.

Sugihartati, R. (2019). Gambang Kromong sebagai Identitas Orang Cina Benteng. Jurnal Desain, 6(02), 129. https://doi.org/10.30998/jurnaldesain.v6i2.2997.

Utami, S. (2018). Kuliner Sebagai Identitas Budaya: Perspektif Komunikasi Lintas Budaya. CoverAge: Journal of Strategic Communication, 8(2), 36-44. https://doi.org/10.35814/coverage.v8i2.588.

Wahid, Z., \& Juhdi, M. (2018). Makna Gotong Royong Dalam Kosmologi Permukiman Tanean Lanjhang Di Madura Sebagai Penguatan Nilai Kebangsaan Dan Nasionalisme. Journal Pendidikan Seni, Bahasa Dan Budaya, 1(1), 11-20. http://ejournal.elbinajatim.com/index.php/jpsb/article/view/4.

Wedasuwari, I. A. M. (2020). Kajian Literatur : Bahasa, Budaya, Dan Pikiran Dalam Linguistik Antropologi. Wacana Saraswati Majalah Ilmiah Tentang Bahasa, Sastra Dan Pembelajarannya, 20(1), 1-5. https://doi.org/10.46444/wacanasaraswati.v20i1.186.

Widianto, E. (2018). Pemertahanan Bahasa Daerah melalui Pembelajaran dan Kegiatan di Sekolah. Jurnal Kredo, 1(2), 1-13. https://jurnal.umk.ac.id/index.php/kredo/article/view/2096.

Wirman, W., Sari, G. G., Asriwandari, H., \& Yesicha, C. (2018). Etnografi Komunikasi Tradisi Bakar Tongkang (Go Ge Cap Lak) di Kabupaten Rokan Hilir. Jurnal ASPIKOM, 3(5), 846. https://doi.org/10.24329/aspikom.v3i5.230.

Yoga, S. (2019). Perubahan Sosial Budaya Masyarakat Indonesia Dan Perkembangan Teknologi Komunikasi. Jurnal Al-Bayan, 24(1). https://doi.org/10.22373/albayan.v24i1.3175.

Yusanto, Y. (2020). Ragam Pendekatan Penelitian Kualitatif. Journal Of Scientific Communication (JSC), 1(1). https://doi.org/10.31506/jsc.v1i1.7764.

Zuriatina, I. (2020). Pengaruh Pembangunan Kebudayaan Terhadap Pembangunan Manusia Di Indonesia. Temali : Jurnal Pembangunan Sosial, 3(1), 1-17. https://doi.org/10.15575/jt.v3i1.6364. 